\title{
Contrasting patterns of turnover between plants, pollinators and their interactions
}

\section{Olivia Norfolk ${ }^{\star}$, Markus P. Eichhorn and Francis S. Gilbert}

School of Life Sciences, University of Nottingham, University Park, Nottingham NG7

2RD, United Kingdom

*Corresponding author: Olivia Norfolk, University of Nottingham, University Park, Nottingham NG7 2RD, United Kingdom, plxon1@nottingham.ac.uk

Running title: Contrasting turnover between plants and pollinators

Article type: Biodiversity Research and Reviews

Word Count: 4,406

\section{ABSTRACT}

\section{Aim}

Biogeographers typically assess patterns of diversity across landscapes. Since interacting groups often exhibit contrasting trends, this leads to variation in the structure of interaction networks and thereby influences ecosystem processes. Here we aim to disentangle how patterns of diversity differ between species (plants, pollinators) and their interactions across an agricultural landscape. The region is known for its irrigated gardens which appear as high diversity islands in the mountainous habitat. We are interested in whether this local enhancement was (a) increasing landscape heterogeneity by supporting novel species, or (b) increasing local diversity by supporting higher densities of species that also occur in the unmanaged habitat.

\section{Location}

South Sinai, Egypt

\section{Methods}

We compared alpha diversity of plants, pollinators and interactions in agricultural gardens and plots of unmanaged habitat in two altitudinal categories, high and low mountains, with high and low habitat quality in the matrix respectively. We then used similarity analyses involving the $\mathrm{C}_{\mathrm{qN}}$ measure to compare levels of turnover across the landscape. 


\section{Results}

The impact of the gardens differed with respect to the landscape context; in the low mountains gardens enhanced the abundance and diversity of plants, pollinators and interactions, but in the high mountains they had no effect. Plants exhibited high levels of turnover, with gardens increasing heterogeneity by supporting novel crop species. In contrast, pollinators exhibited low levels of turnover, with gardens and unmanaged habitat supporting similar species. The diversity of interactions was influenced by the composition of the plant community and showed extremely high levels of turnover.

\section{Main conclusions}

Plants, pollinators and their interactions can display contrasting patterns of turnover across a shared landscape. Although the enhancement of local habitat can boost pollinator diversity, the maintenance of habitat heterogeneity may also be required if you aim to conserve the diversity of interactions between plants and pollinators.

\section{Key words}

beta diversity; desert agriculture; interaction diversity; irrigation; species turnover; visitation network

\section{(A) INTRODUCTION}

Understanding landscape scale patterns of diversity is an important challenge in conservation biogeography because it can help inform which strategies will be most effective at maximising diversity. Beta diversity is maintained across a landscape by two processes, nestedness and spatial turnover (Wright \& Reeves, 1992; Baselga, 2010). Nestedness occurs when less diverse assemblages of species form a nested subset of those present in the entire species pool and usually reflects a non-random process of species exclusion from less diverse sites (Ulrich \& Gotelli, 2007). In contrast, spatial turnover occurs when certain species are actively replaced by others, creating distinct assemblages that each support novel species (Leprieur et al., 2009). It is useful to understand these patterns of beta diversity because communities exhibiting high nestedness versus high spatial turnover require contrasting conservation strategies; in nested communities the targeted conservation of the most diverse habitat patches can benefit the majority of species, but in those with high spatial turnover it is essential to maintain a number of patches with high habitat heterogeneity in order to conserve all the species in the community (Wright \& Reeves, 1992; Baselga, 2010). 
Deciding on the target organism also has a strong influence on the most appropriate conservation strategy because different taxa can display contrasting patterns of beta diversity across a shared landscape (Fleishman et al., 2002; Soininen et al., 2007). Species with higher dispersal abilities tend to show lower levels of turnover (Soininen et al., 2007) and herbivorous insects show much lower levels of spatial turnover than plants due to generalised foraging behaviour (Novotny et al., 2007). Since pollinators are more mobile than plants and their plant-pollinator interactions tend to be generalised (Bjerknes et al., 2007; Graves \& Shapiro, 2003; Williams et al., 2011) they are likely to exhibit much lower levels of turnover than the plants on which they forage.

In reality groups of organisms cannot be considered in isolation, with communities consisting of complex networks of interacting species from different trophic levels (Tylianakis et al., 2010). Conservation is traditionally aimed at rare and threatened species and often fails to take into account the networks of interactions that are responsible for maintaining ecosystem services such as pollination and pest control (Memmott et al., 2004; Fontaine et al., 2005,Tylianakis et al., 2007; Macfadyen et al., 2009). We are currently moving towards a more holistic approach to conservation that focusses on preserving ecosystem functioning (MEA 2005; Balvanera et al., 2006) so must consider how to best conserve the networks of interactions among species. In the context of plants and pollinators, we must decide whether we want to prioritise the conservation of pollinator species or pollination services. If it is the latter, then it may be more useful to focus on conserving plant-pollinator interactions rather than pollinator species per se. In this study we compare patterns of alpha and beta diversity between plants, pollinators and their interactions, in order to disentangle how community structure changes between species and their interactions across a shared landscape.

The unusual distribution of resources associated with our study site in South Sinai makes it an ideal location to compare patterns of landscape scale diversity. It is an arid mountainous region, but the presence of rainwater harvesting allows the cultivation of agricultural gardens with a higher potential for plant growth than unmanaged habitat (Norfolk et al., 2013). These gardens appear as resource-rich islands in an arid landscape and have been shown to support a higher diversity of wild plants and pollinators than the surrounding habitat (Norfolk et al 2013, Norfolk et al 2014). In this study we were interested in how the gardens affected the alpha diversity of plants, pollinators and interactions as compared to those found in the unmanaged habitat.

Landscape context is known to have a strong influence on the composition of pollinator communities (Holzschuh et al., 2007), with the species richness of crop pollinators declining with distance from natural or semi-natural habitat (Ricketts et al., 2008) and increasing with 
the quality of the surrounding habitat (Kennedy et al., 2013). We predicted that impact of the gardens would differ in accordance to the quality of the surrounding habitat. Previous studies have shown that the natural habitat contains a higher abundance and diversity of wild flora at higher altitudes (Norfolk et al., 2013; Ayyad et al., 2000) so we have selected gardens from two altitudinal categories a) the high mountains (isolated, cooler temperatures, higher water availability) and b) the low mountains (close proximity to villages, more disturbed, lower water availability). Specifically we predicted that the irrigated gardens would increase the abundance and alpha diversity of plants, pollinators and interactions above those found in the unmanaged habitat, with a greater effect in the low mountains due to a higher contrast with the quality of the matrix.

We utilised new techniques in similarity analyses (Gotelli \& Chao, 2013) to test two models for explaining how beta diversity was maintained across this agricultural landscape. The first model predicted high levels of spatial turnover, with gardens increasing landscape heterogeneity by supporting novel species that were not present in the unmanaged habitat (Fig 1. (a)). The second model predicted that diversity would be nested, with low levels of turnover across the landscape (Fig 1. (b)). In this model, gardens would create local enhancement by increasing the densities of species that were also present in the unmanaged species pool.

We hypothesised that plants and pollinators would show contrasting levels of turnover and that:

1) Plants would follow the first model, exhibiting high levels of spatial turnover with gardens increasing overall landscape heterogeneity.

2) Pollinators would follow the second model, showing much lower levels of spatial turnover (due to their greater mobility and generalised foraging behaviour) with gardens creating local enhancement.

3) Plant-pollinator interactions would be influenced by the distribution of both plants and pollinators with high levels of spatial turnover across the landscape following the first model.

We found highly contrasting patterns of turnover between plants, pollinators and their interactions, and that patterns of alpha diversity were strongly influenced by the landscape context. 


\section{(A) METHODS}

\section{(B) Study area}

This study was conducted in the St Katherine Protectorate $\left(28^{\circ} 33^{\prime} \mathrm{N}, 33^{\circ} 56^{\prime} \mathrm{E}\right)$ in South Sinai, Egypt. It is an arid, mountainous region with altitudes of 1200-2624 m a.s.l.. The landscape is typified by rugged mountains, interspersed with steep-sided valleys known as wadis. The region has a hyper-arid climate, experiencing extremely dry, hot summers and cold winters. Average annual rainfall ranges from $10 \mathrm{~mm}$ per year in low coastal areas to $50 \mathrm{~mm}$ per year in the high mountains, but this entire annual rainfall can fall within the space of a single day as unpredictable flash floods (Cools et al., 2012). The local Bedouin traditionally farm orchard gardens at the base of the wadis that depend on the runoff rainwater to facilitate the growth of a variety of orchard products as well as vegetables and herbs (Norfolk et al., 2012; Zalat et al., 2008). The gardens are primarily used for subsistence, but also contain ornamental flowers and have been shown to provide important habitat for rare wild native plants (Norfolk et al., 2013). From satellite imaging we have estimated that there are between 500-600 gardens in the St Katherine Protectorate, which form a dense network of walled gardens that run along the base of mountain wadis (Norfolk, O., unpublished data).

Gardens were selected at random from the two altitudinal zones, (a) high mountains, 1800$1850 \mathrm{~m}$ a.s.l. $(\mathrm{N}=9)$, and (b) low mountains, $1300-1550 \mathrm{~m}$ a.s.l. $(\mathrm{N}=10)$. An equal number of unmanaged plots were sampled at the base of the selected wadis, in areas where slope and soil type resembled those found in the neighbouring gardens (Fig. 2). We refer to these as unmanaged plots, because they have no active management and represent the habitat that would be present in the absence of agriculture. Gardens tended to occur in tight clusters along the base of the wadis so the choice of unmanaged plots was highly constrained, but within each wadi all of the gardens and unmanaged plots were within $1 \mathrm{~km}$ of each other, with a mean distance of $461 \mathrm{~m} \pm 73$ between gardens and the nearest controls. The maximum foraging range of many solitary bees is $600 \mathrm{~m}$ (Osborne et al., 1999; Gathmann \& Tscharntke, 2002) and wild pollinators generally respond to landscape factors within a $1 \mathrm{~km}$ radius (Steffan-Dewenter et al., 2002). As such, we can assume that within wadi we are sampling from the same pollinator assemblage, with habitat type (garden versus unmanaged) being the main varying factor. Five contiguous $10 \times 10 \mathrm{~m}^{2}$ quadrats were measured out in each garden and unmanaged plot for four repeat surveys across the season. Gardens ranged from $600-2800 \mathrm{~m}^{2}$ in size, so between $20-80 \%$ of each garden was surveyed. There was no significant difference in garden size between the high mountains and low mountains (Imer: $\mathrm{X}^{2}=1.42, \mathrm{df}=1, \mathrm{P}=0.233$ ), so garden size has not been included in further analyses. 


\section{(B) Flower-visitor surveys}

In order to investigate patterns of diversity in plants and pollinators we conducted monthly plant-pollinator surveys in the selected gardens and unmanaged plots throughout April to July 2013. The total number of fresh flowers (ie. petals and anthers intact and not dried) was recorded for each plant species to allow calculation of floral abundance and plant diversity. For clustered, umbelled or spiked inflorescences the average number of flowers per inflorescence was calculated from three flower heads in the field, with floral abundance calculated as the total number of inflorescences multiplied by the average number of flowers per inflorescence.

Surveys were always carried out during sunny, non-windy days between 9am and 4pm. During sampling a single collector thoroughly searched each $10 \times 10 \mathrm{~m}^{2}$ quadrat in turn and examined all flowering plants. All flower-visiting insects observed were net-collected directly from the plants, unless confident identification was possible in the field (honeybees and certain butterflies), and the identity of the plant species was recorded to establish the interaction. The collector walked at a steady pace around the quadrat searching each flowering plant once; if there were no visitors then the collector continued the walk and moved on to the next plant. When multiple visitors were observed simultaneously on one plant the collector spent no more than five minutes (excluding handling time) catching insects from that particular plant.

Plants were identified in the field where possible or collected for identification using Boulos (2002). Plants were classified as either wild or cultivated, with cultivated defined as any plant actively tended for consumption, household use or ornamental purposes. All captured insects were pinned and identified to species level for orders Hymenoptera and Lepidoptera and family Syrphidae by taxonomists. Coleoptera and non-syrphid Diptera were identified to family level and have been grouped into morphospecies based on visual characteristics to allow network analyses. Capture rates were $92 \%$; visitors that evaded capture were excluded from further analyses since species-level identification was not possible.

\section{(B) Data analyses}

Spatial patterns in alpha diversity were explored using Hill's numbers (species richness $\left[{ }^{0} \mathrm{D}\right]$, the exponential of Shannon entropy $\left[{ }^{1} D\right]$ and the inverse Simpson index $\left.\left[{ }^{2} D\right]\right)$ (Hill, 1973) in accordance with current consensus (Chao et al., 2012; Jost, 2006; Leinster \& Cobbold, 2011). Hill's numbers are defined to the order of $q\left({ }^{a} \mathrm{D}\right)$, whereby parameter $q$ indicates the weighting given to rare or common species. ${ }^{0} \mathrm{D}$ is insensitive to relative frequencies, and is therefore weighted towards rare species. ${ }^{1} D$ is weighted towards common species, and ${ }^{2} D$ is 
weighted towards abundant species. The same concept was also applied to the interactions, with ${ }^{0} \mathrm{D}$ defined as the number of unique links between plant and pollinator species, ${ }^{1} \mathrm{D}$ as the Shannon diversity of these interactions and ${ }^{2} D$ as the inverse Simpson diversity of interactions. Diversity measures were calculated in package vegan in $R$ version 3.0.2 ( $R$ Core Team, 2013; Oksanen et al., 2013). Data from the four-month sampling period were pooled for each garden and unmanaged plot. Pollinator abundance was defined as the total number of insects recorded visiting flowers in each plot, thus is equivalent to the abundance of interactions.

The abundance and diversity $\left({ }^{0} \mathrm{D},{ }^{1} \mathrm{D},{ }^{2} \mathrm{D}\right)$ of plants, pollinators and their interactions were analysed using linear-mixed effect models (Ime4 package)(Bolker et al., 2009). Models included an interaction between altitudinal category (high mountains vs. low mountains) and habitat (garden and unmanaged habitat) as predictors and wadi and as a random factor to account for spatial variation amongst plots. Model fit was based upon AIC and simplification followed Zuur et al. (2009), with the significance of fixed factors tested by comparing models with a likelihood ratio test (distributed as Chi-squared). A Tukey's post-hoc test was used to compare the effect of habitat (garden vs. unmanaged) within the two altitudinal categories.

To visualise the interactions between plants and pollinators at a community level we created cumulative visitation networks for gardens and unmanaged plots in the high and low mountains using R package bipartite (Dormann et al., 2009). These visitation networks were derived from quantitative interaction matrices with $\mathrm{n}$ rows (representing plant species) and $\mathrm{m}$ columns (representing insect species), with the value at the intersect representing the number of interactions observed between flower and insect.

(C) Similarity analyses

In order to evaluate whether the gardens increased species turnover or lead to local enhancement we compared the similarity of species and interactions in the gardens and unmanaged habitats using three measures of beta diversity derived from the $\mathrm{C}_{q N}$ measure (Gotelli \& Chao, 2013). As with the previously described Hill's numbers, $q$ is a parameter that determines the measures' sensitivity to species' relative abundances and $N$ is the number of assemblages (in this case $N=2$ for the high and low mountains respectively). For $q=0, \mathrm{C}_{0 N}$ is the Sorenson similarity index; for $q=1, C_{1 N}$ is the Horn overlap index; and for $q=2, C_{2 N}$ is the Morisita-Horn similarity index. These three similarity indices were calculated for flowervisitors, flowers and their interactions in SPADE using 200 iterations (Chao \& Shen, 2010). $\mathrm{C}_{q N}$ ranges between unity (when communities are identical) and zero (when communities are completely different). Higher similarity means more species shared between gardens and unmanaged plots and would indicate there is potential to increase local diversity. Lower 
similarity means fewer shared species and would indicate that the gardens are supporting a distinct community of species thus increasing landscape heterogeneity.

The Sorenson similarity index was also used (with 200 iterations) to estimate the total relative abundance of the shared species and interactions in (a) the garden assemblage and (b) the unmanaged assemblage (ie. the proportion of species within the garden that were shared with the unmanaged habitat, and vice versa). This provided additional insight into whether any dissimilarity was due to the two habitats supporting a completely different suite of species, or whether dissimilarity was due to the presence of additional species within the gardens.

\section{(A) RESULTS}

\section{(B) Plant-pollinator interactions in the gardens and unmanaged habitat}

In total we recorded 2410 interactions between 159 pollinator species and 81 plant species. The average number of observed interactions was $88 \pm 13$ in the gardens and $37 \pm 9$ in the unmanaged habitat. Visitation networks (Fig 3.). Plants, pollinators and their interactions displayed significant statistical interactions between habitat type (garden/ unmanaged) and altitude (Table 1), with gardens having a much stronger positive effect upon abundance and diversity in the low mountains.

In the high mountains, habitat type had little impact upon plant abundance (Mean \pm S.E. garden: $68.67 \pm 5.39$; unmanaged: $70.33 \pm 6.48$ ) or pollinator abundance (garden: $56.22 \pm$ 9.80; unmanaged: $45.89 \pm 10.47$ ) and garden and unmanaged plots supported similar levels of plant and pollinator diversity $\left({ }^{0} \mathrm{D},{ }^{1} \mathrm{D}\right.$ and ${ }^{2} \mathrm{D}$ ) (Fig 4. (a)\&(b)). The diversity of plantpollinator interactions $\left({ }^{0} \mathrm{D},{ }^{1} \mathrm{D}\right.$ and $\left.{ }^{2} \mathrm{D}\right)$ did not differ between gardens and unmanaged habitat (Fig 4. (c)) which can be visualised by the similar complexities of the visitation networks (Fig 3. (a)). In the low mountains, habitat type had a much stronger effect, with gardens supporting a more abundant and diverse community of plants and pollinators than the unmanaged habitat. Plant abundance was twice as high within the low mountain gardens (Garden: $98.20 \pm 10.14$; Unmanaged habitat: $47.40 \pm 7.37$ ) and pollinator abundance increased by seven-fold (Garden: $117 \pm 21.09$, Unmanaged: $18.10 \pm 13.16$ ). Plant diversity $\left({ }^{0} \mathrm{D},{ }^{1} \mathrm{D}\right.$ and $\left.{ }^{2} \mathrm{D}\right)$ and pollinator diversity $\left({ }^{0} \mathrm{D}\right.$ and $\left.{ }^{1} \mathrm{D}\right)$ were also significantly higher within the gardens than the unmanaged habitat, with plant and pollinator species richness doubling within the gardens (Fig 4. (a)\&(b). The diversity of their interactions was higher still $\left({ }^{0} \mathrm{D},{ }^{1} \mathrm{D}\right.$ and ${ }^{2} D$ ), with the richness of interactions increasing four-fold within the gardens (Fig 4. (c)). 
The ten most abundant pollinator species for each habitat are shown in Appendix S2. In the high mountains, seven of these ten species occurred in gardens and unmanaged habitats, with Megachile walkeri the dominant species in both. In the low mountains, six of these ten species occurred in gardens and unmanaged habitats and Syritta fasciata and Apis mellifera were the dominant species in both. In accordance with the Hill's diversity estimates, which decreased sharply across the order of $q$ (Fig. 3), there tended to be several dominant and abundant species accompanied by much higher numbers of rare species.

\section{(B) Species similarity of plants, pollinators and their interactions}

Plants exhibited low levels of similarity between gardens and unmanaged plots in both the high and low mountains, with the similarity of interactions lower still (Fig. 5). In contrast, pollinators exhibited much higher levels of similarity between gardens and unmanaged plots in both the high and low mountains (Fig. 5). The similarity of plants and interactions decreased steeply to the order of $q$, suggesting that there was high similarity between the presence/absence of species in the gardens and unmanaged plots, but that there were important differences in the relative frequency of dominant species and that when these differences were accounted for the similarity between the two communities decreased.

The vast majority of plants and pollinators observed within the unmanaged plots were shared with the gardens with approximately $90 \%$ of the species and interactions from the natural habitat also found within the gardens (Fig. 6). Within the gardens, the majority of pollinators were shared with the natural habitat, but the proportion of shared plants and interactions was considerably lower with approximately half of all plants and interactions unique to the gardens. This suggests that the dissimilarities in community structure are primarily due to the presence of novel plant species and interactions within the gardens and not due to a loss of species or interactions in either habitat.

\section{(A) DISCUSSION}

Plants and pollinators showed highly contrasting patterns of landscape scale diversity. As predicted, plants followed the first model (Fig. 1(a)), with gardens increasing overall landscape heterogeneity by supporting a distinct assemblage of species that was highly dissimilar to that found in the unmanaged habitat. Pollinators exhibited extremely low levels of turnover across the landscape, with gardens increasing local diversity (in the low mountains) by supporting higher densities of species that were also present in the unmanaged species pool (Fig. 1(b)). The identity of the plant-pollinator interactions was strongly affected by the composition of the plant communities, with pollinators showing the ability to modify their foraging behaviour. Thus interactions showed even higher levels of 
turnover than the plants, with gardens and unmanaged habitats containing extremely dissimilar networks of interactions despite supporting the same pollinator species.

\section{(B)The impact of the gardens and the importance of landscape context}

The quality of the surrounding habitat affected how the pollinator community responded to the presence of the agricultural gardens. At higher altitudes the natural habitat is relatively undisturbed with a higher availability of water and contains a high abundance and diversity of wild flora (Norfolk et al., 2013; Ayyad et al., 2000). In this high quality habitat, gardens supported an equally abundant and diverse plant community as the unmanaged habitat and had no impact upon the abundance or diversity of pollinators or interactions. Conversely, in the low mountains where natural floral resources were scarce, the gardens actively increased the abundance and diversity of pollinators and interactions. Both ornamental and agricultural gardens have been known to boost pollinator abundances in other resourcelimited habitats, such as desert environments (Gotlieb et al., 2011), heavily developed cities (Matteson et al., 2008) and intensively managed farmlands (Samnegård et al., 2011) and these agricultural gardens seem to have a similar positive effect upon pollinator abundances in the low mountains where the surrounding environment is particularly sparse.

Gardens in the poorer-quality landscape received twice as many pollinators as those in the high mountain gardens, despite gardens supporting an equal abundance and species richness of flora. These inflated abundances could be indicative of a crowding effect in the low mountains, with gardens acting as florally-rich islands that collect species from the surrounding sparse habitat. The crowding effect has been documented for arthropods in highly fragmented habitats (Collinge \& Forman, 1998; Debinski, 2000; Zhao et al., 2011), and predicts that when habitat is removed from a landscape, surviving individuals in the disturbed matrix will move into the remaining habitat fragments leading to elevated densities (Grez et al., 2004). In a reversal of typical habitat fragmentation, the human-modified gardens may be acting as resource-rich islands in the low quality desert habitat, resulting in elevated densities of pollinators within the gardens. In recently fragmented habitats, crowding effects tend to be transient, with inflated densities adjusting to a lower equilibrium within a matter of months (Debinski, 2000; Grez et al., 2004), though abundances can be maintained through sustained immigration from neighbouring populations (Bowman et al., 2002). The gardens in the low mountains all date back 50 years or more (Gilbert, 2011), so the high abundances of pollinators are unlikely to be transient, but it is possible they are being maintained through sustained immigration from the high mountains.

\section{(B) Contrasting turnover between plants, pollinators and their interactions}


Plants exhibited high levels of spatial turnover across the landscape, with distinct communities of species in the gardens and the unmanaged habitat. This was primarily due to the additional presence of cultivated species within the gardens and was not a reflection of a loss of wild plant species, with gardens supporting the vast majority of wild flowers (95\%) and interactions (85\%) that were present in the unmanaged habitat. Other studies in the region have shown that the gardens contain a higher diversity of wild plants than the natural habitat (Norfolk et al., 2013), suggesting that these rainwater irrigated gardens are having a positive role in the conservation of native flora in this region.

The presence of cultivated flora led a major restructuring of the plant-pollinator interaction networks, with changes in interaction diversity directly reflecting the modified plant community within the gardens. Pollinators were able to adapt to the novel floral resources within the gardens, with interactions with cultivated flora augmenting those with wild species. Such generalised foraging behaviour has been observed in other systems, with many alien flowers receiving substantial levels of visitation from native pollinators (Bjerknes et al., 2007; Graves \& Shapiro, 2003; Williams et al., 2011). Alien flora can become well integrated in visitation networks (Memmott \& Waser, 2002; Vilà et al., 2009) to such an extent that the simulated removal of alien plants can lead to species extinctions when flower-visitors fail to reorganise their interactions (Valdovinos et al., 2009). In accordance with other studies, cultivated flora (some of which were alien to the region) were deeply integrated into visitation networks within the gardens and provided important resources for native pollinators.

This is one of the first studies to utilise the $\mathrm{C}_{\mathrm{qN}}$ similarity analyses described by Gotelli and Chao (2013), and utilising three measures of both alpha and beta diversity has provided greater insight into the relative abundance of rare, common and abundant species within the two habitats. Pollinators showed an uneven distribution of alpha diversity in both habitats, with high number of rare species. This phenomenon of widespread rarity appears to be pervasive in bee communities (Williams et al., 2001), and high numbers of singleton species accompanied by several dominant species have been noted in communities of desert bees elsewhere in the Middle East (Potts et al., 2003; Gotlieb et al., 2011) and in North America (Hostetler \& McIntyre, 2001; Minckley, 2014).

Levels of beta diversity also decreased sharply to the order of $q$ for plants, pollinators and their interactions, suggesting that the relative frequency of dominant species (and interactions) differed between the gardens and unmanaged habitats. For plants, this pattern likely reflects the fact that actively cultivated flora tended to be more abundant, thus dominant within the gardens, with the less abundant wild species shared with the unmanaged habitat. Although the vast majority of pollinator species occurred in both habitats 
(high similarity based upon presence/absence), the modification of the floral community within the gardens seems to have influenced the relative abundances of these species resulting in different dominant species in each habitat.

\section{(B) Conclusions}

Our results highlight the promising potential of arid land agriculture for pollinator conservation, by demonstrating that the rain-fed gardens in this system are able to maintain and in cases actively enhance pollinator abundance and diversity. On a broader scale, we show that interacting species can display highly contrasting patterns of turnover across a shared landscape and provide a clear conceptual framework for explaining the patterns of turnover exhibited by plants, pollinators and their interactions. In this system the enhancement of local habitat had the potential to boost pollinator numbers, but habitat heterogeneity was also required in order to maintain the diversity of plant-pollinator interactions. In terms of management, these results suggests that improvement of local habitat and habitat heterogeneity are both important tools in conservation, but that a combined approach may be necessary in order to conserve the diversity of interactions between species.

\section{Acknowledgements}

We would like to thank The Leverhulme Trust for funding; our local guide N. Mansour for his invaluable help and support in the field; the staff and manager M. Qotb at the St Katherine Protectorate for permissions and assistance; the Egyptian Environmental Affairs Agency for permission to work in the Park; H. Mubarak and all the staff at Fox Camp for providing facilities; and our team of taxonomists who kindly donated their time and expertise, $C$. O'Toole (Apidae), M. Kuhlmann and H. Dathe (Colletidae), A. Pauly (Halictidae), C. Praz and A. Muller (Megachillidae), C. Schmid-Egger (Sphecidae) and Amnon Freidberg (Tephritidae); Our research programme was set up in collaboration with Dr S. Zalat.

\section{References}

Ayyad, M.A., Fakhry, A.M. \& Moustafa, A.R.A. (2000) Plant biodiversity in the St. Catherine area of the Sinai peninsula, Egypt. Biodiversity Conservation, 9, 265-281.

Balvanera, P., Pfisterer, A.B., Buchmann, N., He, J.-S., Nakashizuka, T., Raffaelli, D. \& Schmid, B. (2006) Quantifying the evidence for biodiversity effects on ecosystem functioning and services. Ecology Letters, 9, 1146-1156.

Baselga, A. (2010) Partitioning the turnover and nestedness components of beta diversity. Global Ecology and Biogeography, 19, 134-143. 
Bjerknes, A.-L., Totland, Ø., Hegland, S.J. \& Nielsen, A. (2007) Do alien plant invasions really affect pollination success in native plant species? Biological Conservation, 138, $1-12$

Bolker, B.M., Brooks, M.E., Clark, C.J., Geange, S.W., Poulsen, J.R., Stevens, M.H.H. \& White, J.-S.S. (2009) Generalized linear mixed models: a practical guide for ecology and evolution. Trends in Ecology \& Evolution, 24, 127-135.

Boulos, L. (2002) Flora of Egypt. Al Hadara Publishing, Cairo.

Bowman, J., Cappuccino, N. \& Fahrig, L. (2002) Patch size and population density: the effect of immigration behavior. Conservation Ecology, 6, 9.

Chao, A., Chiu, C.-H. \& Hsieh, T.C. (2012) Proposing a resolution to debates on diversity partitioning. Ecology, 93, 2037-2051.

Chao, A, Shen, TJ (2010) Program SPADE (Species Prediction and Diversity Estimation). Program and User's Guide. Published at http,//chao.stat.nthu.edu.tw.

Collinge, S.K. \& Forman, R.T. (1998) A conceptual model of land conversion processes: predictions and evidence from a microlandscape experiment with grassland insects. Oikos, 82, 66-84.

Cools, J., Vanderkimpen, P., El Afandi, G., Abdelkhalek, A., Fockedey, S., El Sammany, M., Abdallah, G., El Bihery, M., Bauwens, W. \& Huygens, M. (2012) An early warning system for flash floods in hyper-arid Egypt. Natural Hazards and Earth System Sciences, 12, 443-457.

Debinski, D.M. \& Holt, R.D. (2000) A Survey and Overview of Habitat Fragmentation Experiments. Conservation Biology, 14, 342-355.

Dormann, C.F., J, F., Bluethgen, N. \& Gruber, B. (2009) Indices, graphs and null models: analyzing bipartite ecological networks. The Open Ecology Journal, 2, 7-24.

Fleishman, E., Betrus, C., Blair, R., Mac Nally, R. \& Murphy, D. (2002) Nestedness analysis and conservation planning: the importance of place, environment, and life history across taxonomic groups. Oecologia, 133, 78-89.

Fontaine, C., Dajoz, I., Meriguet, J. \& Loreau, M. (2005) Functional diversity of plantpollinator interaction webs enhances the persistence of plant communities. PLoS biology, 4, e1.

Gathmann, A. \& Tscharntke, T. (2002) Foraging ranges of solitary bees. Journal of Animal Ecology, 71, 757-764.

Gilbert, H. (2011) 'This is Not Our Life, It's Just a Copy of Other People's': Bedu and the Price of 'Development' in South Sinai. Nomadic Peoples, 15, 7-32.

Gotelli, NJ, Chao, A (2013) Measuring and estimating species richness, species diversity, and biotic similarity from sampling data. pp. 195-211 in: Levin SA (ed.). Encyclopedia of Biodiversity, 2nd edition. Vol. 5. Academic Press, Waltham, MA. 
Gotlieb, A., Hollender, Y. \& Mandelik, Y. (2011) Gardening in the desert changes bee communities and pollination network characteristics. Basic and Applied Ecology, 12, 310-320.

Graves, S.D. \& Shapiro, A.M. (2003) Exotics as host plants of the California butterfly fauna. Biological Conservation, 110, 413-433.

Grez, A., Zaviezo, T., Tischendorf, L. \& Fahrig, L. (2004) A Transient, Positive Effect of Habitat Fragmentation on Insect Population Densities. Oecologia, 141, 444-451.

Hill, M.O. (1973) Diversity and Evenness: A Unifying Notation and Its Consequences. Ecology, 54, 427-432.

Holzschuh, A., Steffan-Dewenter, I., Kleijn, D. \& Tscharntke, T. (2007) Diversity of flowervisiting bees in cereal fields: effects of farming system, landscape composition and regional context. Journal of Applied Ecology, 44, 41-49.

Hostetler, N.E. \& McIntyre, M.E. (2001) Effects of urban land use on pollinator (Hymenoptera: Apoidea) communities in a desert metropolis. Basic and Applied Ecology, 2, 209-218.

Jost, L. (2006) Entropy and diversity. Oikos, 113, 363-375.

Kennedy, C.M., Lonsdorf, E., Neel, M.C., Williams, N.M., Ricketts, T.H., Winfree, R., Bommarco, R., Brittain, C., Burley, A.L., Cariveau, D., Carvalheiro, L.G., Chacoff, N.P., Cunningham, S.A., Danforth, B.N., Dudenhöffer, J.-H., Elle, E., Gaines, H.R., Garibaldi, L.A., Gratton, C., Holzschuh, A., Isaacs, R., Javorek, S.K., Jha, S., Klein, A.M., Krewenka, K., Mandelik, Y., Mayfield, M.M., Morandin, L., Neame, L.A., Otieno, M., Park, M., Potts, S.G., Rundlöf, M., Saez, A., Steffan-Dewenter, I., Taki, H., Viana, B.F., Westphal, C., Wilson, J.K., Greenleaf, S.S. \& Kremen, C. (2013) A global quantitative synthesis of local and landscape effects on wild bee pollinators in agroecosystems. Ecology Letters, 16, 584-599.

Leinster, T. \& Cobbold, C.A. (2011) Measuring diversity: the importance of species similarity. Ecology, 93, 477-489.

Leprieur, F., Olden, J.D., Lek, S. \& Brosse, S. (2009) Contrasting patterns and mechanisms of spatial turnover for native and exotic freshwater fish in Europe. Journal of Biogeography, 36, 1899-1912.

Macfadyen, S., Gibson, R., Polaszek, A., Morris, R.J., Craze, P.G., Planqué, R., Symondson, W.O.C. \& Memmott, J. (2009) Do differences in food web structure between organic and conventional farms affect the ecosystem service of pest control? Ecology Letters, 12, 229-238.

Matteson, K.C., Ascher, J.S. \& Langellotto, G.A. (2008) Bee Richness and Abundance in New York City Urban Gardens. Annals of the Entomological Society of America, 101, 140-150.

MEA: Millennium Ecosystem Assessment (2005) Ecosystems and human well-being. Island Press Washington, DC. 
Memmott, J. \& Waser, N.M. (2002) Integration of alien plants into a native flower-pollinator visitation web. Proceedings of the Royal Society of London. Series B: Biological Sciences, 269, 2395-2399.

Memmott, J., Waser, N.M. \& Price, M.V. (2004) Tolerance of pollination networks to species extinctions. Proceedings of the Royal Society of London. Series B: Biological Sciences, 271, 2605-2611.

Minckley, R.L. (2014) Maintenance of richness despite reduced abundance of desert bees (Hymenoptera: Apiformes) to persistent grazing. Insect Conservation and Diversity, 7, 263-273.

Norfolk, O., Abdel-Dayem, M. \& Gilbert, F. (2012) Rainwater harvesting and arthropod biodiversity within an arid agro-ecosystem. Agriculture, Ecosystems \& Environment, 162, 8-14.

Norfolk, O., Eichhorn, M.P. \& Gilbert, F. (2013) Traditional agricultural gardens conserve wild plants and functional richness in arid South Sinai. Basic and Applied Ecology, 14, 659669.

Norfolk, O. \& Gilbert, F. (2014) Insect visitation rates to wild flowers increase in the presence of arid agriculture in South Sinai, Egypt. Journal of Arid Environments. In Press

Novotny, V., Miller, S.E., Hulcr, J., Drew, R.A.I., Basset, Y., Janda, M., Setliff, G.P., Darrow, K., Stewart, A.J.A. \& Auga, J. (2007) Low beta diversity of herbivorous insects in tropical forests. Nature, 448, 692-695.

Oksanen, J., Guillaume Blanchet, F., Kindt, F., Legendre, P., Minchin, P. R., O'Hara, R. B., Simpson, G.L., Solymos, P. M., Stevens, H. H. \& Wagner, H. (2013). vegan: Community Ecology Package. R package version 2.0-9. http://CRAN.Rproject.org/package =vegan

Osborne, J.L., Clark, S.J., Morris, R.J., Williams, I.H., Riley, J.R., Smith, A.D., Reynolds, D.R. \& Edwards, A.S. (1999) A landscape-scale study of bumble bee foraging range and constancy, using harmonic radar. Journal of Applied Ecology, 36, 519-533.

Potts, S.G., Vulliamy, B., Dafni, A., Ne'eman, G. \& Willmer, P. (2003) Linking bees and flowers: how do floral communities structure pollinator communities? Ecology, 84, 2628-2642.

R Core Team (2013) R: A language and environment for statistical computing. R Foundation for Statistical Computing, Vienna, Austria. http://www.R-project.org/.

Ricketts, T.H., Regetz, J., Steffan-Dewenter, I., Cunningham, S.A., Kremen, C., Bogdanski, A., Gemmill-Herren, B., Greenleaf, S.S., Klein, A.M., Mayfield, M.M., Morandin, L.A., Ochieng', A. \& Viana, B.F. (2008) Landscape effects on crop pollination services: are there general patterns? Ecology Letters, 11, 499-515.

Samnegård, U., Persson, A.S. \& Smith, H.G. (2011) Gardens benefit bees and enhance pollination in intensively managed farmland. Biological Conservation, 144, 2602 2606. 
Soininen, J., Lennon, J.J. \& Hillebrand, H. (2007) A multivariate analysis of beta diversity across organisms and environments. Ecology, 88, 2830-2838.

Steffan-Dewenter, I., Münzenberg, U., Bürger, C., Thies, C. \& Tscharntke, T. (2002) Scaledependent effects of landscape context on three pollinator guilds. Ecology, 83, 1421 1432.

Tylianakis, J.M., Tscharntke, T. \& Lewis, O.T. (2007) Habitat modification alters the structure of tropical host-parasitoid food webs. Nature, 445, 202-205.

Tylianakis, J.M., Laliberté, E., Nielsen, A. \& Bascompte, J. (2010) Conservation of species interaction networks. Biological Conservation, 143, 2270-2279.

Ulrich, W. \& Gotelli, N.J. (2007) Null model analysis of species nestedness patterns. Ecology, 88, 1824-1831.

Valdovinos, F.S., Ramos-Jiliberto, R., Flores, J.D., Espinoza, C. \& López, G. (2009) Structure and dynamics of pollination networks: the role of alien plants. Oikos, 118, 1190-1200.

Vilà, M., Bartomeus, I., Dietzsch, A.C., Petanidou, T., Steffan-Dewenter, I., Stout, J.C. \& Tscheulin, T. (2009) Invasive plant integration into native plant-pollinator networks across Europe. Proceedings of the Royal Society B: Biological Sciences, 276, 38873893.

Williams, N. M., Minckley, R.L. \& Silveira, F.A. (2001) Variation in native bee faunas and its implications for detecting community change. Conservation Ecology. 5, 57-89.

Williams, N.M., Cariveau, D., Winfree, R. \& Kremen, C. (2011) Bees in disturbed habitats use, but do not prefer, alien plants. Basic and Applied Ecology, 12, 332-341.

Wright, D. \& Reeves, J. (1992) On the meaning and measurement of nestedness of species assemblages. Oecologia, 92, 416-428.

Zalat, S. \& Gilbert, F. (2008) Gardens in a sacred landscape: Bedouin heritage and natural history in the high mountains of Sinai. American University in Cairo Press, Cairo.

Zhao, Z., Wang, Y., Dahan, H., Rong, Z., Mengmeng, Z. \& Dong, F. (2011) Effects of habitat loss and fragmentation on species loss and colonization of insect communities in experimental alfalfa landscapes. Biodiversity Science, 19, 453-462.

Zuur, A., leno, E.N., Walker, N., Savelieve, A.A. \& Smith, G.M. (2009) Mixed Effects Models and Extensions in Ecology with $R$, 1 st Edition edn. Springer.

\section{Supporting Information}

Additional Supporting Information may be found in the online version of this article:

Appendix S1 List of plant species in the visitation networks.

Appendix S2 The most common flower-visitors observed in gardens and control plots. 


\section{Biosketches}

Olivia Norfolk is a PhD student at the University of Nottingham. Her current research focuses upon the impact that traditional agricultural practices have upon patterns of diversity in arid South Sinai.

Markus Eichhorn is a plant ecologist whose research investigates the formation of habitat structures and their implications for the diversity and composition of dependent communities. Francis Gilbert is an Associate Professor at the University of Nottingham whose research interests include the biology and conservation of the fauna and flora of South Sinai and their relationship to the indigenous people. 
Table 1. Results of linear mixed-effect models comparing the two habitats (garden versus unmanaged) and the interaction between altitudinal category (high mountain vs. low mountain). Models contained abundance or diversity as the response variable, habitat and altitudinal category as fixed effects and wadi as a random effect. $d f=1$ in all models.

\begin{tabular}{|c|c|c|c|c|c|c|}
\hline \multirow[b]{4}{*}{ Plants } & \multicolumn{6}{|c|}{ Results of linear mixed-effect models } \\
\hline & \multicolumn{2}{|c|}{ Habitat * Altitude } & \multicolumn{2}{|c|}{ Habitat } & \multicolumn{2}{|c|}{ Altitude } \\
\hline & $x^{2}$ & $P$ & $x^{2}$ & $P$ & $x^{2}$ & $P$ \\
\hline & & & & & & \\
\hline $\mathrm{N}$ & 13.15 & $<0.001$ & 2.58 & 0.108 & 0.03 & 0.860 \\
\hline${ }^{u} \mathrm{D}$ & 8.31 & 0.004 & 7.39 & 0.007 & 0.18 & 0.671 \\
\hline${ }^{1} \mathrm{D}$ & 7.32 & 0.007 & 10.83 & $<0.001$ & 1.23 & 0.257 \\
\hline${ }^{2} \mathrm{D}$ & 4.99 & 0.025 & 9.41 & 0.002 & 0.16 & 0.692 \\
\hline \multicolumn{7}{|c|}{ Pollinators } \\
\hline $\mathrm{N}$ & 19.54 & $<0.001$ & 1.13 & 0.285 & 1.68 & 0.195 \\
\hline${ }^{u} \mathrm{D}$ & 12.54 & $<0.001$ & 1.18 & 0.276 & 0.54 & 0.460 \\
\hline${ }^{1} \mathrm{D}$ & 5.45 & 0.020 & 3.18 & 0.074 & 0.01 & 0.988 \\
\hline${ }^{2} \mathrm{D}$ & 1.366 & 0.243 & 1.73 & 0.188 & 0.01 & 0.959 \\
\hline \multicolumn{7}{|c|}{ Interactions } \\
\hline${ }^{0} \mathrm{D}$ & 19.89 & $<0.001$ & 1.06 & 0.304 & 1.46 & 0.226 \\
\hline${ }^{1} \mathrm{D}$ & 10.78 & 0.001 & 3.85 & 0.049 & 0.07 & 0.788 \\
\hline${ }^{2} \mathrm{D}$ & 10.14 & 0.001 & 1.26 & 0.262 & 0.58 & 0.447 \\
\hline
\end{tabular}


Figure 1 Two conceptual models describing patterns of diversity between gardens and unmanaged habitat in the high mountains (HM) and low mountains (LM). (a) High spatial turnover: predicts that gardens and unmanaged habitat will support distinct assemblages of novel species. (b) High nestedness: predicts that gardens will increase diversity by supporting higher numbers of species that were already present in the unmanaged species pool.

Figure 2 Map of study site in St Katherine Protectorate, South Sinai, with locations of gardens and unmanaged plots.

Figure 3 Quantitative bipartite networks of interactions between flowers and insect-visitors in gardens and unmanaged habitats (based upon pooled data). In each network the rectangles represent plants (bottom row) and pollinators (top row) and the connecting lines represent links between species. The width of the rectangle represents the total number of interactions, and the widths of the connecting lines represent the number of interactions observed for that link. The insects in the top row are grouped by taxonomic groups for simplicity, though interaction analyses within the text were performed on a species level and were based upon individual networks. Plants in the bottom rows represent species, with species names listed in Appendix S1.

Figure 4 Mean Hill's diversity of (a) plants, (b) pollinators, and (c) their interactions, for $q=0,1,2$. Each bar compares the mean diversity $( \pm$ S.E.) between gardens $(G)$ and unmanaged plots $(U M)$ in the two altitudinal categories, high mountains (HM) and low mountains (LM). Asterisks represent a significant difference between gardens and unmanaged habitat within altitudinal categories as determined by Tukey post-hoc tests.

Figure 5 The similarity profile $C_{q N}$ of species and interactions in gardens and unmanaged plots for (a) high mountains and (b) low mountains, for $q=0,1,2 . C_{q N}$ ranges between unity (when communities are identical) and zero (when communities are completely different). Error bars represent standard errors estimated from 200 iterations.

Figure 6 Mean relative abundance of shared species and interactions in the all gardens and natural plots, estimated using an adjusted Sorenson's similarity index with 200 iterations, error bars represent standard errors. 
FIG 1-6 (High quality images sent to Josephine de Mink) 
Appendix S1. Plant species in the visitation networks.

\begin{tabular}{|c|c|}
\hline & Plant species \\
\hline$A$ & Astralagus sp. \\
\hline$A C$ & Allium cepa \\
\hline AK & Arabidopsis kneuckeri \\
\hline AM & Anchusa milleri \\
\hline $\mathrm{AO}$ & Alkanna orientalis \\
\hline AP & Anarrhinum pubescens \\
\hline AP1 & Asperugo procubens \\
\hline AS & Achillea santolina \\
\hline AS1 & Alcea striata \\
\hline AT & Astragalus tribuloides \\
\hline BB & Bituminaria bituminosa \\
\hline BO & Borago officinalis \\
\hline $\mathrm{BU}$ & Ballota undulata \\
\hline BV & Beta vulgaris \\
\hline CA & Convolvulus arvensis \\
\hline CG & Carduus getulus \\
\hline $\mathrm{CH}$ & Caylusea hexagyna \\
\hline $\mathrm{Cl}$ & Colutea istria \\
\hline $\mathrm{CP}$ & Capparis spinosa \\
\hline $\mathrm{CP}$ & Cucurbita pepo \\
\hline CS & Centaurea scoparia \\
\hline CS1 & Crataegua sinaica \\
\hline CS2 & Crepis sancta \\
\hline DA & Diplotaxis acris \\
\hline $\mathrm{DH}$ & Diplotaxis harra \\
\hline$E G$ & Echinops glaberrimus \\
\hline EG1 & Erodium glaucophyllum \\
\hline ES & Eruca sativa \\
\hline FM & Fagonia mollis \\
\hline FS & Ferulla sinaica \\
\hline FV & Foeniculum vulgare \\
\hline GC & Gypsophila capillaris \\
\hline GS & Gomphocarpus sinaicus \\
\hline $\mathrm{HA}$ & Helianthus annuus \\
\hline $\mathrm{HB}$ & Hyoscyamus boveanus \\
\hline HP & Hyosyarus pusillas \\
\hline IC & Ipomea cairica \\
\hline IL & Isatis Iusitanica \\
\hline L & Lamiacae unknown sp. \\
\hline LC & Lantana camara \\
\hline LN & Launaea nudicaulis \\
\hline LP & Lavandula pubescens \\
\hline LS & Launaea spinosa \\
\hline
\end{tabular}




\begin{tabular}{ll}
\hline M & Mesembryanthemum sp. \\
MA & Matthiola arabica \\
ML & Matthiola longipetala (livida) \\
ML1 & Mentha longifolia \\
MLS & Mentha longifolia schimperi \\
MN & Monsonia nivea \\
MS & Medicago sativa \\
NR & Nicotiana rustica \\
OB & Ochradenus baccatus \\
OL & Oligomeris linifolia \\
OS & Origanum syriacum \\
P & Papaver somniferum \\
P1 & Papaver sp. \\
PA & Phlomis aurea \\
PC & Petroselinum crispum \\
PD & Prunus dulcis \\
PG & Punica granatum \\
PH & Peganum harmala \\
PO & Portulaca oleracea \\
PR & Paracaryus ruglosum \\
PV & Phaseolus vulgaris \\
R & Rosa sp. \\
RC & Rosa canina \\
RO & Rosmarinus officinalis \\
SA & Stachys aegyptiaca \\
SM & Salvia multicaulis \\
SN & Solanum nigrum \\
SX & Scrophularia xanthoglossa \\
TS & Tanacetum santolinoides \\
UK1 & Asteraceae sp.1 \\
UK2 & Asteraceae sp.2 \\
VS & Verbascum sinaiticum \\
VV & Vitis vinifera \\
ZS & Zilla spinosa \\
\hline
\end{tabular}


Appendix S2. The most common flower-visitors observed in gardens and control plots

\begin{tabular}{|c|c|c|c|c|c|c|c|c|c|c|c|}
\hline \multirow[b]{2}{*}{ Garden } & \multicolumn{4}{|c|}{ High Mountain (>1800m) } & \multirow[b]{2}{*}{ (\% visits) } & \multicolumn{6}{|c|}{ Low Mountain (1500m ) } \\
\hline & $\mathrm{N}$ & (\% visits) & Unmanaged & $\mathrm{N}$ & & Garden & $\mathrm{N}$ & (\% visits) & Unmanaged & $\mathrm{N}$ & (\% visits) \\
\hline $\begin{array}{l}\text { Megachile (Eutricharaea) } \\
\text { walkeri Dalla Torre } 1896\end{array}$ & 84 & $(17 \%)$ & $\begin{array}{l}\text { Megachile } \\
\text { walkeri }\end{array}$ & 60 & $(15 \%)$ & Syritta fasciata & 281 & $(20 \%)$ & Syritta fasciata & 24 & $(13 \%)$ \\
\hline $\begin{array}{l}\text { Hylaeus (Dentigera) } \\
\text { sinaiticus (Alfken 1938) }\end{array}$ & 59 & $(12 \%)$ & $\begin{array}{l}\text { Lassioglossum } \\
\text { (Dialictus) } \\
\text { collopiense } \\
\text { (Perez 1903) }\end{array}$ & 56 & $(14 \%)$ & Apis mellifera $\mathrm{L}$. & 155 & $(11 \%)$ & Apis mellifera & 15 & $(8 \%)$ \\
\hline Omophlus sp. & 33 & $(6 \%)$ & $\begin{array}{l}\text { Anthophora } \\
\text { pauperata } \\
\text { Walker } 1871\end{array}$ & 16 & $(4 \%)$ & Lampides boeticus & 101 & $(7 \%)$ & $\begin{array}{l}\text { Seladonia } \\
\text { smaragdula }\end{array}$ & 11 & $(6 \%)$ \\
\hline $\begin{array}{l}\text { Seladonia smaragdula } \\
\text { (Vachal 1895) }\end{array}$ & 25 & $(5 \%)$ & $\begin{array}{l}\text { Capitites augur } \\
\text { (Frauenfeld) }\end{array}$ & 16 & $(4 \%)$ & $\begin{array}{l}\text { Coccinella } \\
\text { septempunctata }\end{array}$ & 78 & $(5 \%)$ & Halictus tibialis & 11 & $(6 \%)$ \\
\hline Lampides boeticus $\mathrm{L}$. & 23 & $(5 \%)$ & $\begin{array}{l}\text { Hylaeus } \\
\text { sinaiticus }\end{array}$ & 16 & $(4 \%)$ & Hylaeus sinaiticus & 72 & $(5 \%)$ & Quartiniasp. & 9 & $(5 \%)$ \\
\hline $\begin{array}{l}\text { Eupeodes corrolae } \\
\text { (Fabricius 1794) }\end{array}$ & 17 & $(5 \%)$ & $\begin{array}{l}\text { Seladonia } \\
\text { smaragdula }\end{array}$ & 15 & $(4 \%)$ & Attagenus sp. & 70 & $(5 \%)$ & $\begin{array}{l}\text { Coccinella } \\
\text { septempunctata }\end{array}$ & 8 & $(4 \%)$ \\
\hline $\begin{array}{l}\text { Syritta fasciata } \\
\text { Wiedemann } 1830\end{array}$ & 15 & $(3 \%)$ & Halictus tibialis & 13 & $(3 \%)$ & Hylaeus sp. & 48 & $(3 \%)$ & $\begin{array}{l}\text { Lampides } \\
\text { boeticus }\end{array}$ & 6 & $(3 \%)$ \\
\hline $\begin{array}{l}\text { Coccinella } \\
\text { septempunctata } \mathrm{L} .\end{array}$ & 13 & (3\%) & Omophlus sp. & 12 & $(3 \%)$ & Megachile walkeri & 47 & (3\%) & $\begin{array}{l}\text { Hoplitis } \\
\text { (Anthocopa) sp. }\end{array}$ & 6 & $(3 \%)$ \\
\hline $\begin{array}{l}\text { Capitites augur } \\
\text { (Frauenfeld) }\end{array}$ & 13 & (3\%) & $\begin{array}{l}\text { Eupeodes } \\
\text { corrolae }\end{array}$ & 11 & $(3 \%)$ & $\begin{array}{l}\text { Anthophora } \\
\text { pauperata }\end{array}$ & 36 & $(2 \%)$ & $\begin{array}{l}\text { Anthophora } \\
\text { pauperata }\end{array}$ & 5 & $(3 \%)$ \\
\hline $\begin{array}{l}\text { Halictus tibialis Walker } \\
1871\end{array}$ & 13 & $(3 \%)$ & Quartinia sp. & 10 & $3 \%$ & $\begin{array}{l}\text { Seladonia } \\
\text { smaragdula }\end{array}$ & 27 & $2 \%$ & $\begin{array}{l}\text { Pontia daplidice } \\
\text { L. }\end{array}$ & 5 & $3 \%$ \\
\hline
\end{tabular}


